\title{
Role of metabolites of cyclophosphamide in cardiotoxicity
}

\author{
Koichiro Kurauchi, Takuro Nishikawa* (0, Emiko Miyahara, Yasuhiro Okamoto and Yoshifumi Kawano
}

\begin{abstract}
Background: The dose-limiting toxic effect of cyclophosphamide (CY) is cardiotoxicity. The pathogenesis of myocardial damage is poorly understood, and there is no established means of prevention. In previous studies, we suggested that for CY-induced cardiotoxicity, whereas acrolein is the key toxic metabolite, carboxyethylphosphoramide mustard (CEPM) is protective. We sought to verify that acrolein is the main cause of cardiotoxicity and to investigate whether aldehyde dehydrogenase (ALDH), which is associated with greater CEPM production, is involved in the protective effect for cardiotoxicity. We also evaluated the protective effect of $\mathrm{N}$-acetylcysteine (NAC), an amino acid with antioxidant activity and a known acrolein scavenger.

Methods: H9c2 cells were exposed to CY metabolites HCY (4-hydroxy-cyclophosphamide), acrolein or CEPM. The degree of cytotoxicity was evaluated by MTT assay, lactate dehydrogenase (LDH) release, and the production of reactive oxygen species (ROS). We also investigated how the myocardial cellular protective effects of CY metabolites were modified by NAC. To quantify acrolein levels, we measured the culture supernatants using high performance liquid chromatography. We measured ALDH activity after exposure to HCY or acrolein and the same with pre-treatment with NAC.

Results: Exposure of H9c2 cells to CEPM did not cause cytotoxicity. Increased ROS levels and myocardial cytotoxicity, however, were induced by HCY and acrolein. In cell cultures, HCY was metabolized to acrolein. Less ALDH activity was observed after exposure to $\mathrm{HCY}$ or acrolein. Treatment with NAC reduced acrolein concentrations.

Conclusions: Increased ROS generation and decreased ALDH activity confirmed that CY metabolites HCY and acrolein are strongly implicated in cardiotoxicity. By inhibiting ROS generation, increasing ALDH activity and decreasing the presence of acrolein, NAC has the potential to prevent CY-induced cardiotoxicity.
\end{abstract}

Keywords: Acrolein, Aldehyde dehydrogenase, Cardiotoxicity, Cyclophosphamide, N-acetylcysteine

\section{Background}

Hematopoietic stem cell transplantation (HSCT) is a radical but risky treatment for hematopoietic diseases. For HSCT, alkylating agent cyclophosphamide (CY) is one of the mainstay drugs, used in high doses during most conditioning regimens [1]. Recently, administration of posttransplantation CY (PTCy) in high doses has also been attracting attention as a novel strategy for preventing graft-versus-host disease (GVHD) [2,3].

$\mathrm{CY}$ is a prodrug activated by the hepatic cytochrome P-450 (CYP) enzyme system to produce

\footnotetext{
*Correspondence: adu44150@ams.odn.ne.jp

Department of Pediatrics, Graduate School of Medical and Dental

Sciences, Kagoshima University, Sakuragaoka 8-35-1, Kagoshima City,

Kagoshima Prefecture 890-8520, Japan
}

4-hydroxycyclophosphamide (HCY), which forms in equilibrium with aldocyclophosphamide (AldoCY). Depending on cell type, AldoCY may, through the chemical process of $\beta$-elimination, decompose to form cytotoxic phosphoramide mustard (PM) and byproduct acrolein, or may be mediated by aldehyde dehydrogenase (ALDH), to inactive metabolite $o$-carboxyethyl-phosphoramide mustard (CEPM) [4, 5] (Fig. 1).

As reported in several cases, the dose-limiting toxicity of CY is cardiotoxicity, which has been observed only after high-dose CY therapy [6-8]. Most severely, with attendant risk of sudden death, this may manifest as hemorrhagic necrotic perimyocarditis. On the basis of postmortem examination, the pathophysiology of highdose CY-associated cardiac toxicity is thought to depend 


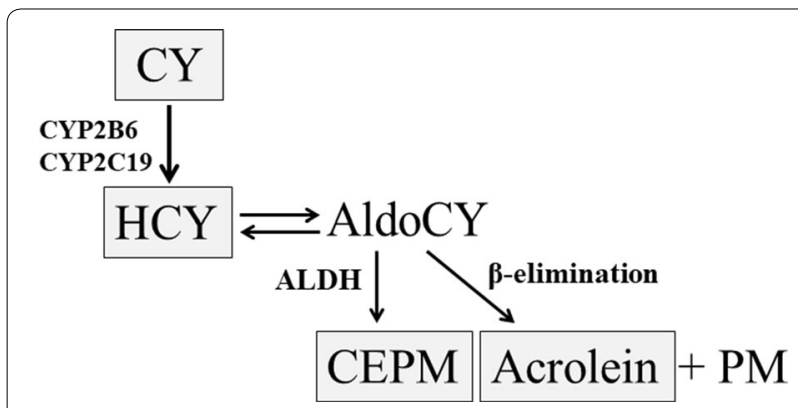

Fig. 1 Cyclophosphamide metabolic pathways. Cyclophosphamide (CY) is metabolized to 4-hydroxy-cyclophosphamide (HCY) in the hepatic cytochrome P-450 enzyme (CYP) system (CYP2B6 and/ or CYP2C19). HCY enters cells as tautomer aldocyclophosphamide (AldoCY). Through $\beta$-elimination, AldoCY can be converted to phosphoramide mustard (PM) and acrolein. Alternatively, AldoCY can also be oxidized to the inactive metabolite o-carboxyethylphosphoramide mustard (CEPM) by aldehyde dehydrogenase (ALDH)

on toxic endothelial damage followed by extravasation of toxic metabolites, resulting in myocyte damage, interstitial hemorrhage, and edema $[9,10]$.

The pathogenesis of myocardial damage is poorly understood, and there is no established means of prevention. In our previous study [11], to evaluate myocardial cell injury by CY, we exposed rat cardiac myocardial cell line $\mathrm{H} 9 \mathrm{c} 2$ to $\mathrm{CY}$ metabolized in the $\mathrm{S} 9$ fraction of rat liver homogenates. There was no evidence of myocardial cell injury from $\mathrm{CY}$ alone, such injury was only evident when $\mathrm{CY}$ was metabolized in vitro [11]. We speculated that the pathogenesis of myocardial cell injury was possibly due to an increase in acrolein and apoptosis. Subsequently, we found that co-exposure with $\mathrm{N}$-acetylcysteine (NAC), an amino acid with antioxidant activity and a known acrolein scavenger [12], was able to suppress myocardial cell injury. It seemed that the mechanisms of NAC protection against CY-induced cardiotoxicity involved inhibition of apoptosis, acrolein suppression, and increased production of CEPM [11]. We consequently decided to investigate whether ALDH activity plays a role in lessening myocardial cell injury by increasing the production of CEPM.

We sought to convincingly demonstrate that acrolein is the main cause of CY-induced cardiotoxicity and to investigate how to cause the cytotoxic activity for $\mathrm{H} 9 \mathrm{c} 2$ cardiomyocytes. We also evaluated the relationship between myocardial cell injury and ALDH activity.

\section{Methods}

\section{Reagents}

CY (Cat. \#C0768), dimethyl sulfoxide (DMSO: Cat. \#D2650), NAC (Cat. \#A9165), and metaphosphoric acid (MPA: Cat. \#239275) were purchased from SIGMAAldrich (St. Louis, MO), HCY (Cat. \#sc-206885) and
CEPM (Cat. \#sc-207411) were purchased from Santa Cruz Biotechnology (Dallas, TX). Acrolein (Cat. \#M-815B/5031-03) was purchased from AccuStandard (New Haven, CT). CY and NAC were diluted with normal saline. $\mathrm{HCY}$ and CEPM were diluted with phosphatebuffered saline (PBS) and DMSO, respectively.

\section{Cell culture}

H9c2 cell line embryonic rat cardiomyocytes (Cat. \#CRL1446) were supplied by the American Type Culture Collection (ATCC, Manassas, VA). The H9c2 specimens were maintained in DMEM medium (Cat. \#11995-065; Life Technologies, Carlsbad, CA) containing 10\% fetal bovine serum (FBS: Cat. \#30-2020; also from ATCC) at $37^{\circ} \mathrm{C}$ in a humidified atmosphere with $5 \%$ carbon dioxide $\left(\mathrm{CO}_{2}\right)$.

\section{Analysis of cell viability}

H9c2 cells were plated at $2.5 \times 10^{4}$ cells $/ \mathrm{mL}$ density in 24-well plates and grown overnight. These samples were exposed to CY $(250 \mu \mathrm{M})$, HCY $(10$ or $30 \mu \mathrm{M})$, CEPM $(10$ or $30 \mu \mathrm{M})$ or acrolein $(10$ or $30 \mu \mathrm{M})$ at $37{ }^{\circ} \mathrm{C}$ in $5 \%$ $\mathrm{CO}_{2}$ for 24 or $48 \mathrm{~h}$. After the addition to each sample of $50 \mu \mathrm{L}$ of $5 \mathrm{mg} / \mathrm{mL}$ of 3-(4,5-dimethyl-2-thiazolyl)-2,5-diphenyl- $2 H$-tetrazolium bromide (MTT: Cat. \#345-01821; Dojindo, Kumamoto, Japan), samples were incubated at $37{ }^{\circ} \mathrm{C}$ in $5 \% \mathrm{CO}_{2}$ for $2 \mathrm{~h}$. Formazan crystals were dissolved by adding $1 \mathrm{~mL}$ of DMSO and, using a microplate reader (Infinite M200, Tecan, Mannedorf, Switzerland), and this data was analyzed using i-Control Ver. 1.0 software (Tecan).

To investigate the influence of NAC, before exposure to $\mathrm{CY}$ or $\mathrm{CY}$ metabolites, $\mathrm{H} 9 \mathrm{c} 2$ cells were incubated for $2 \mathrm{~h}$ with 10\% FBS supplemented DMEM containing $1 \mathrm{mM}$ NAC. For these protocols, we conservatively selected a known nontoxic concentration, $1 \mathrm{mM}$, of NAC [11]. After pre-treatment, the medium of each sample was replaced with fresh medium containing NAC along with $\mathrm{CY}$ or $\mathrm{CY}$ metabolites. In parallel protocols, the morphology of H9c2 cells after exposure, in the 24-well culture plates, to $\mathrm{CY}$ or CY metabolites was observed using $100 \times$ magnification fluorescence microscopy (Axio Observer Z1; Zeiss MicroImaging GmbH, Göttingen, Germany). For control, unexposed H9c2 cells were seeded in 24-well plates at $2.5 \times 10^{4}$ cells $/ \mathrm{mL}$ density in DMEM with $5 \%$ FBS and incubated at $37^{\circ} \mathrm{C}$ in $5 \% \mathrm{CO}_{2}$.

\section{Measurement of intracellular ROS generation}

To detect intracellular ROS, we used dichlorofluorescin diacetate (DCFH-DA) molecular probes (Cat. \#D6883; SIGMA-Aldrich) as our previous study [11]. Briefly, H9c2 cells were harvested and re-suspended in ice-cold PBS. And then, $5 \mathrm{mM}$ DCFH-DA was added to the cell 
suspension. After $15 \mathrm{~min}$ of incubation at $37{ }^{\circ} \mathrm{C}$ in $5 \%$ $\mathrm{CO}_{2} 10$ or $30 \mathrm{mM} \mathrm{HCY}$ or $30 \mathrm{mM}$ acrolein was added and incubated $37{ }^{\circ} \mathrm{C}$ in $5 \% \mathrm{CO}_{2}$ for $15 \mathrm{~min}$. The fluorescence intensity was evaluated using a flow cytometer (Accuri C6, Becton, Dickinson, \& Co., Mountain View, $\mathrm{CA}$ ), and data were analyzed using C6 software (ver. 1.0.264.21). For NAC treatment, cells were pretreated with $1 \mathrm{mM} \mathrm{NAC}$ for $2 \mathrm{~h}$, after which, the cells were collected and exposed to $\mathrm{HCY}$ or acrolein as described above.

\section{Measurement of lactate dehydrogenase release}

The presence of lactate dehydrogenase (LDH), regarded as a marker of cellular injury, was measured in cell-culture supernatant. H9c2 cells $\left(1.25 \times 10^{4}\right.$ cells/well) were cultured overnight in 96-well plates. After incubation, the cells were exposed to HCY (1.25$40 \mu \mathrm{M})$ and acrolein $(3-100 \mu \mathrm{M})$ at $37{ }^{\circ} \mathrm{C}$ in $5 \% \mathrm{CO}_{2}$. After $8 \mathrm{~h}$ incubation, the amount of LDH released in the medium of each sample was assayed, according to the manufacturer's instructions, using LDH Cytotoxicity Detection Kits (Cat. \#MK401; Takara, Shiga, Japan). LDH catalyzes the dehydrogenation of lactic acid and produces pyruvic acid and NADH. This NADH reduces the tetrazolium salt with the catalyst of diaphorase and forms red formazan that absorbs $490 \mathrm{~nm}$ wavelength radiation. Consequently, LDH activity can be evaluated by measuring $490 \mathrm{~nm}$ absorbance. Briefly, after $8 \mathrm{~h}$ incubation, $100 \mu \mathrm{L}$ samples of medium were placed in each well of new 96-well plates. Then, $100 \mu \mathrm{L}$ of reaction mix was added to each well. After $30 \mathrm{~min}$ incubation, using a microplate reader (Infinite M200, Tecan, Mannedorf, Switzerland), $492 \mathrm{~nm}$ absorbance was measured, along with background absorbance at $600 \mathrm{~nm}$, and the data analyzed using i-Control Ver. 1.0 software (Tecan).

\section{Measurement of acrolein concentration in cell culture by high performance liquid chromatography}

H9c2 cells were exposed to $10 \mu \mathrm{M} \mathrm{HCY}$ for $2 \mathrm{~h}$. After $2 \mathrm{~h}$ exposure, cell culture supernatants were collected and acrolein was measured using a colorimetric method based on the specific reaction of acrolein with m-aminophenol in the presence of hydroxylamine [13]. Using the method of Bohnenstengel et al. [11, 14], the amount of acrolein was determined by high performance liquid chromatography (HPLC).

H9c2 cells were also exposed to $100 \mu \mathrm{M}$ acrolein for $4 \mathrm{~h}$ with and without $1 \mathrm{mM}$ NAC. After $4 \mathrm{~h}$ exposure, cell culture supernatants were collected and the amount of acrolein was determined by the sample extraction and HPLC methods described in the preceding paragraph.

\section{Detection of apoptosis by evaluation of caspase-3} and caspase-7 activity

To detect apoptosis, caspase- 3 and caspase- 7 activity was evaluated. As described above in "Analysis of cell viability", $\mathrm{H} 9 \mathrm{c} 2$ cells were plated at $2.5 \times 10^{4}$ cells $/ \mathrm{mL}$ density in 24-well plates and exposed to $30 \mu \mathrm{M} \mathrm{HCY}$ or 30 or $100 \mu \mathrm{M}$ acrolein for $4 \mathrm{~h}$. After different treatments, the supernatants were removed and cells were washed with PBS. Then, the PBS was replaced with $500 \mu \mathrm{L}$ of phenolred-free DMEM supplemented with 10\% FBS. Finally, a drop of CellEvent Caspase 3/7 Green ReadyProbes reagent (Cat. \# R37111; Life Technologies) was added to each well and incubated for $30 \mathrm{~min}$ at $37^{\circ} \mathrm{C}$ in $5 \% \mathrm{CO}_{2}$, and the cells were observed using $100 \times$ magnification fluorescence microscopy (Axio Observer Z1). To stain live cell nuclei, a drop of NucBlue Live Cell Stain ReadyProbes reagent (Cat. \#R37605; Life Technologies), which includes Hoechst 33342 fluorescence dye, was added to each well for $20 \mathrm{~min}$ at room temperature. We conducted this procedure for the products of three experiments. Live cells were consequently stained blue and apoptotic cells green.

\section{Measurement of cellular glutathione content}

Amounts of intracellular glutathione (GSH) were evaluated using NWLSS Glutathione Assay kits (Northwest Life Science Specialties, LLC, Vancouver, WA). H9c2 cells were plated at $2.5 \times 10^{4}$ cells $/ \mathrm{mL}$ density in $25 \mathrm{~cm}^{2}$ tissue culture flasks, and grown, at $37{ }^{\circ} \mathrm{C}$ in $5 \% \mathrm{CO}_{2}$, to $90 \%$ confluence. After incubation, the cells were exposed to $30 \mu \mathrm{M}$ of acrolein, with and without, NAC at $37^{\circ} \mathrm{C}$ in $5 \% \mathrm{CO}_{2}$. For experiments with NAC, the cells were pretreated as described above in "Analysis of cell viability", and then incubated for $2 \mathrm{~h}$ at $37^{\circ} \mathrm{C}$ in $5 \% \mathrm{CO}_{2}$. Untreated cell samples were used for control. After treatment, cells were collected and assayed for GSH content as described in our previous report [11].

\section{Evaluation of ALDH activity}

ALDH activity was analyzed using PicoProbe Aldehyde Dehydrogenase Activity Fluorometric Assay kits (BioVision Inc., Milpitas, CA). Briefly, in $25 \mathrm{~cm}^{2}$ tissue culture flasks, $\mathrm{H} 9 \mathrm{c} 2$ cells were plated at $2.5 \times 10^{4}$ cells $/ \mathrm{mL}$ density and grown, at $37{ }^{\circ} \mathrm{C}$ in $5 \% \mathrm{CO}_{2}$, to $90 \%$ confluence. After incubation, the cells were exposed, at $37^{\circ} \mathrm{C}$ in $5 \% \mathrm{CO}_{2}$, to $10 \mu \mathrm{M} \mathrm{HCY}$ or $30 \mu \mathrm{M}$ acrolein, with and without $1 \mathrm{mM}$ NAC. For experiments with NAC, the cells were pre-treated as described above in "Analysis of cell viability", and then exposed, at $37^{\circ} \mathrm{C}$ in $5 \% \mathrm{CO}_{2}$, for $4 \mathrm{~h}$ to $\mathrm{HCY}$ or acrolein with NAC. Untreated cells were used for control. After treatment, cells were collected and twice washed with ice-cold PBS. The cells were then 
re-suspended with assay buffer and homogenized by sonication. The lysates were centrifuged at $12,000 \mathrm{rpm}$ for $5 \mathrm{~min}$ at $4{ }^{\circ} \mathrm{C}$ and the supernatant was collected. This supernatant was diluted 20 -fold with assay buffer. Thus treated, the supernatant was collected and, according to the manufacturer's instructions, assayed for GSH content.

\section{Statistical analysis}

Data are presented as mean \pm standard deviation (SD). Statistical analysis was performed using StatView version 5.0 for Windows (SAS, Institute Inc., Cary, NC). Treatment effects were established by nonparametric Wilcoxon tests. A probability value of less than 0.05 was considered to be statistically significant.

\section{Results}

Myocardial cytotoxicity induced by $\mathrm{HCY}$ and acrolein

Assay results for MTT showed that exposures to CY, CEPM or $10 \mu \mathrm{M}$ acrolein did not induce cytotoxicity. Myocardial cytotoxicity did ensue, however, after 24 and $48 \mathrm{~h}$ exposure to 10 or $30 \mu \mathrm{M} \mathrm{HCY}$ and $30 \mu \mathrm{M}$ acrolein (Fig. 2a, b; $p<0.05$ ). Intracellular levels of ROS were evaluated from fluorescence intensity measured by flow cytometry: in 10 or $30 \mu \mathrm{M} \mathrm{HCY}$ and $30 \mu \mathrm{M}$ acrolein samples, intracellular levels of ROS were higher than in control samples (Fig. 2c; $p<0.05$ ). LDH release assay results showed greater presence in 10,20 or $40 \mu \mathrm{M} \mathrm{HCY}$ $(p<0.05)$ and $100 \mu \mathrm{M}$ acrolein $(p<0.05)$ samples than in low-dose $\mathrm{HCY}(3 \mu \mathrm{M})$ or acrolein $(1.25 \mu \mathrm{M}$; Fig. $2 \mathrm{~d})$ samples. The average concentration of acrolein in cell culture media after $2 \mathrm{~h}$ exposure to $10 \mu \mathrm{M} \mathrm{HCY}$ was $1.5 \pm 0.07 \mu \mathrm{M}$ (Fig. 2e).

\section{Inhibition of $\mathrm{CY}$ metabolites-induced cell cytotoxicity by NAC}

MTT assay results of 24- and 48-h samples showed that NAC inhibited cytotoxicity induced by CY metabolites (HCY, acrolein) compared with control samples (Fig. 3a, b; $p<0.05)$.

\section{Optical and fluorescence images of $\mathrm{H} 9 \mathrm{c} 2$ cells exposed to $\mathrm{CY}$ metabolites and CY metabolites plus NAC}

Live-cell imaging of samples, in 24-well plates, with cell density of $2.5 \times 10^{4}$ cells $/ \mathrm{mL}$, also revealed acute cytotoxicity in the presence of $\mathrm{CY}$ metabolites and inhibition of this by NAC (Fig. 4a-e). Samples with CY metabolites without NAC, showed shrunken or irregularly shaped cells; but in samples with NAC, cells had a very similar appearance to those in control samples. The protective effect of NAC on H9c2 cells was further verified using Hoechst 33342 staining and fluorescent assays of caspase-3/7 activity. In Fig. 4d, e, cells treated with NAC and challenged by $\mathrm{CY}$ metabolites have the same kind of round nuclei and homogeneous blue fluorescence intensity as normal cells. As Fig. 4c shows, caspase-3 and caspase-7 activity was greater in $100 \mu \mathrm{M}$ acrolein samples; such activity was suppressed in samples pre-treated for $2 \mathrm{~h}$ with $1 \mathrm{mM} \mathrm{NAC} \mathrm{(Fig.} \mathrm{4e).}$

\section{NAC inhibited ROS generation associated with CY metabolites}

After exposure to $30 \mu \mathrm{M} \mathrm{HCY}$ and $30 \mu \mathrm{M}$ acrolein, myocytes in samples that had been pretreated with NAC showed statistically significantly less ROS generation (Fig. 5a).

\section{NAC inhibited GSH depletion associated with acrolein}

Exposure to $30 \mu \mathrm{M}$ of acrolein was statistically significantly $(\mathrm{p}<0.05)$ associated with decreased cardiomyocyte GSH. No such decrease was apparent in myocyte samples pre-treated with NAC and then exposed to acrolein (Fig. 5b).

\section{NAC inhibited lessening of ALDH activity by $\mathrm{CY}$ metabolites}

Compared with control samples, exposure to $30 \mu \mathrm{M} \mathrm{HCY}$ or $30 \mu \mathrm{M}$ acrolein was statistically significantly associated with less ALDH activity. The same kind of samples pretreated with NAC, showed statistically significantly more ALDH activity than those that were not pretreated (Fig. 5c).

\section{Acquisition of acrolein by NAC}

The average concentration of acrolein in cell culture media after $4 \mathrm{~h}$ exposure to $100 \mu \mathrm{M}$ acrolein was $13.2 \pm 0.94 \mu \mathrm{M}$. With NAC, however, after exposure to the same concentration for the same time, the average acrolein concentration was $10.6 \pm 0.37 \mu \mathrm{M}$ (Fig. 5d). This confirms that NAC captured acrolein in the samples.

\section{Discussion}

Since the mechanism of fatal cardiotoxicity that may attend high-dose $\mathrm{CY}$ has not yet been elucidated, and no definitive risk factors have yet been identified, we investigated possible cardiotoxic mechanisms. This follows our previous report on $\mathrm{CY}$ cardiotoxicity using $\mathrm{CY}$ metabolized by rat liver homogenate, S9 (CYS9) in vitro. Results indicated that $\mathrm{CY}$ itself is not cardiotoxic, rather, the harm is caused by CY metabolites [11]. It remained unclear, however, specifically how CY metabolites are involved in cardiotoxicity. Our findings suggested that acrolein plays a major role in $\mathrm{CY}$ cardiotoxicity. We designed the current study to investigate, by exposing $\mathrm{H} 9 \mathrm{c} 2$ cells to $\mathrm{CY}$ metabolites, which metabolites are implicated in cardiotoxicity. 

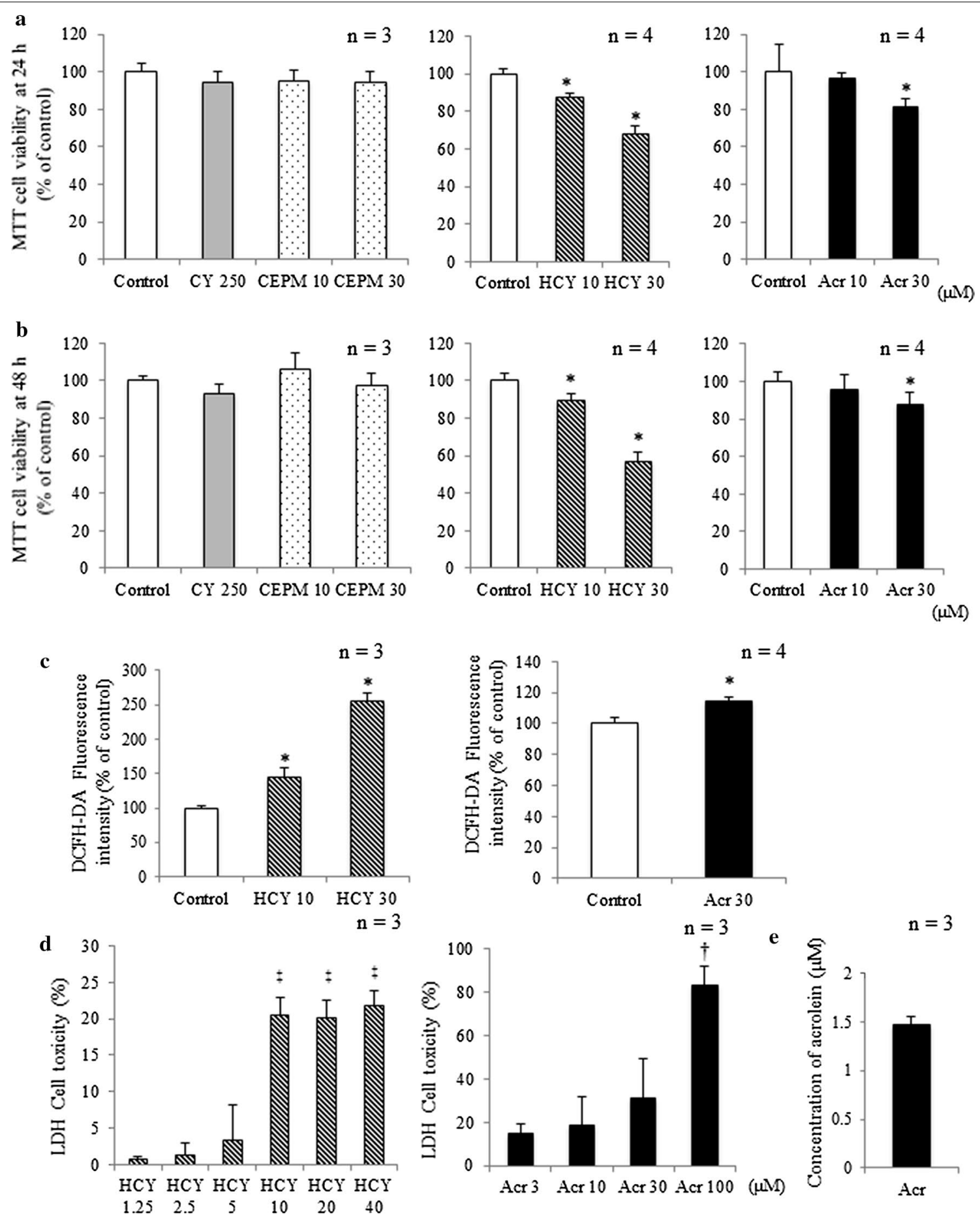

Fig. 2 Myocardial cytotoxicity induced by HCY or acrolein. $\mathrm{H} 9 \mathrm{c} 2$ cell viability after $\mathbf{a}$ 24-h and $\mathbf{b}$ 48-h exposure to CY alone and CY metabolites was assessed by MTT assay (mean + SD from 3 to 4 independent experiments). c Fluorescence intensities, corresponding to levels of $\mathrm{H}_{2} \mathrm{O}_{2}$, in control samples or cells exposed to 10 or $30 \mu \mathrm{M} \mathrm{HCY}$ and $30 \mu \mathrm{M}$ acrolein for $15 \mathrm{~min}$ (mean + SD from 3 to 4 independent experiments). Fluorescence intensity is shown in arbitrary units. $\mathbf{d} \mathrm{LDH}$ release from $\mathrm{H} 9 \mathrm{c} 2$ cells exposed to $\mathrm{HCY}$ and acrolein for $8 \mathrm{~h}$ (mean $+\mathrm{SD}$ from three independent experiments). e Concentration of acrolein in cell culture medium after exposure to $10 \mu \mathrm{M} \mathrm{HCY}$. H9c2 cells were exposed for $2 \mathrm{~h}$ to $\mathrm{HCY}$. Changing concentrations of acrolein in culture media were evaluated using HPLC. ${ }^{*} p<0.05$ compared with control. ${ }^{\dagger} p<0.05$ compared with $3 \mu \mathrm{M}$ acrolein. ${ }^{\ddagger} p<0.05$ compared with $1.25 \mu \mathrm{M} \mathrm{HCY}$ 

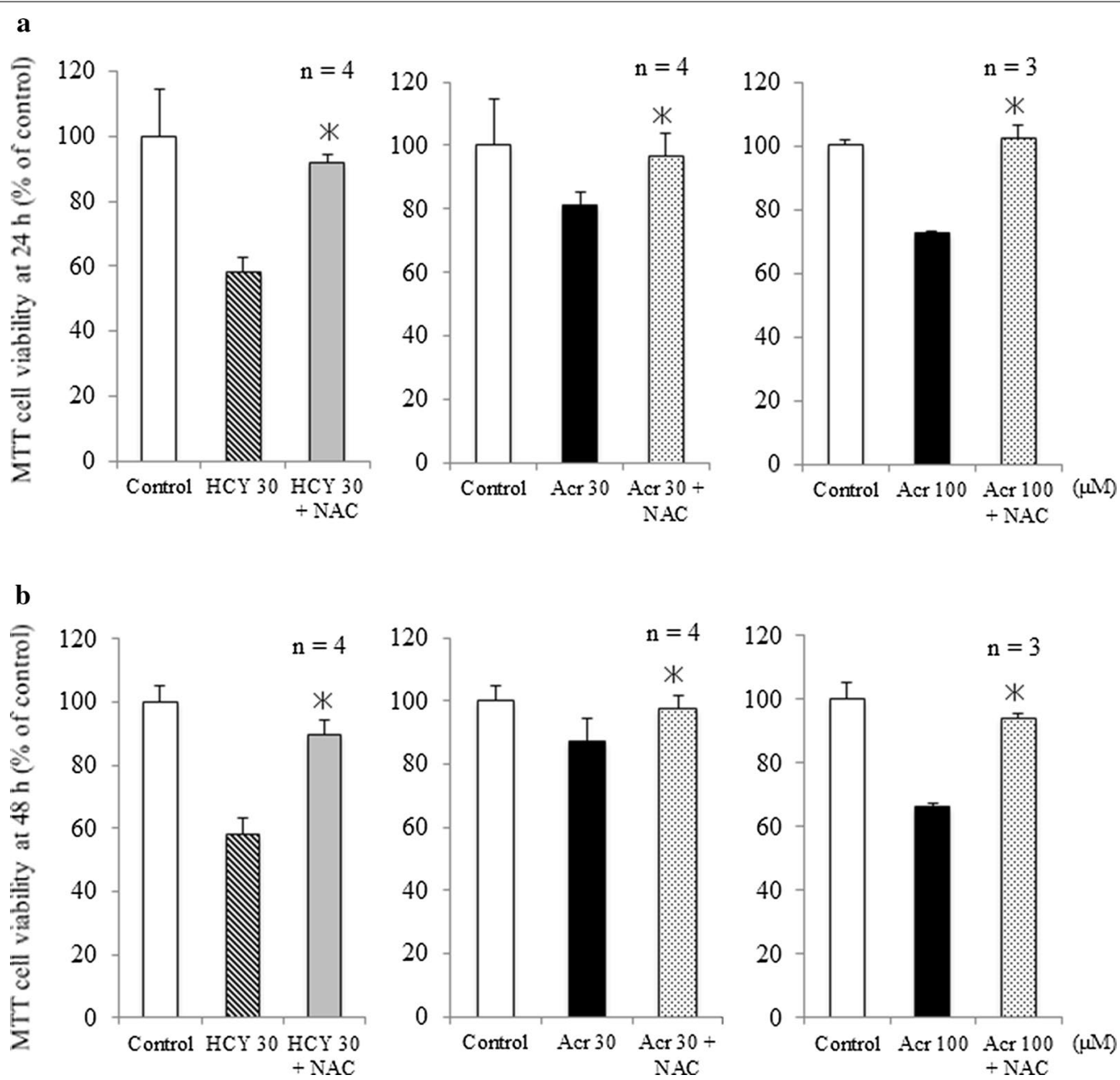

Fig. 3 Inhibition by NAC of cell cytotoxicity induced by CY metabolites. a Effect of NAC on cytotoxicity of CY metabolites in H9c2 cells after 24-h exposure (mean + SD from 3 to 4 independent experiments conducted in duplicate). b Effect of NAC on cytotoxicity of CY metabolites in H9c2 cells after 48-h exposure (mean + SD from 3 to 4 independent experiments conducted in duplicate). c Effect of NAC on ROS generated by CY metabolites, as shown by fluorescence intensity of DCFH-DA in cells exposed for 15 min to $30 \mu \mathrm{M} \mathrm{HCY}$ or $30 \mu \mathrm{M}$ acrolein plus NAC. Fluorescence intensity is shown in arbitrary units (mean + SD from three independent experiments). ${ }^{*} p<0.05$ compared with samples without NAC

The concentrations of the three CY metabolites used in this study were determined based on results from pharmacokinetic studies of high-dose cyclophosphamide in patients and from in vitro studies [11]. While CEPM did not exhibit myocardial cytotoxicity, $\mathrm{HCY}$ at concentrations of 10 and at $30 \mu \mathrm{M}$, and acrolein at $30 \mu \mathrm{M}$ were clearly cytotoxic at 24 and $48 \mathrm{~h}$ (Fig. 2a, b). We further tested whether $\mathrm{HCY}$ was converted to acrolein in the cell culture and found, after $2 \mathrm{~h}$ exposure to $10 \mu \mathrm{M} \mathrm{HCY}$, that the concentration of acrolein in cell culture medium was about $1.5 \mu \mathrm{M}$ (Fig. 2e). There was an ongoing conversion of $\mathrm{HCY}$ to acrolein in the culture medium. HCY itself is probably cardiotoxic, but it causes more damage if converted to acrolein. Besides being a CY metabolite, acrolein is also a ubiquitous environmental pollutant: as a reactive aldehyde, it is of great concern to public health. In recent years, acrolein has been implicated in cardiac diseases $[15,16]$, and it is a known cause of CY-induced hemorrhagic cystitis [17]. Another basic study has suggested that acrolein may be involved in hepatic disorders, including veno-occlusive disease [18].

We previously showed that NAC inhibits CY-induced cardiotoxicity [11], and our present results from MTT assay, Hoechst33342 staining and fluorescent assays of caspase-3/7 activity indicate that NAC also inhibits cardiotoxicity induced both by $\mathrm{HCY}$ and by acrolein (Figs. 3, 4). In either case, pre-treatment with NAC inhibited the production of intracellular ROS (Fig. 5a). This finding is consistent with other reports attributing CY-induced cardiotoxicity to an increase in free oxygen radicals and 


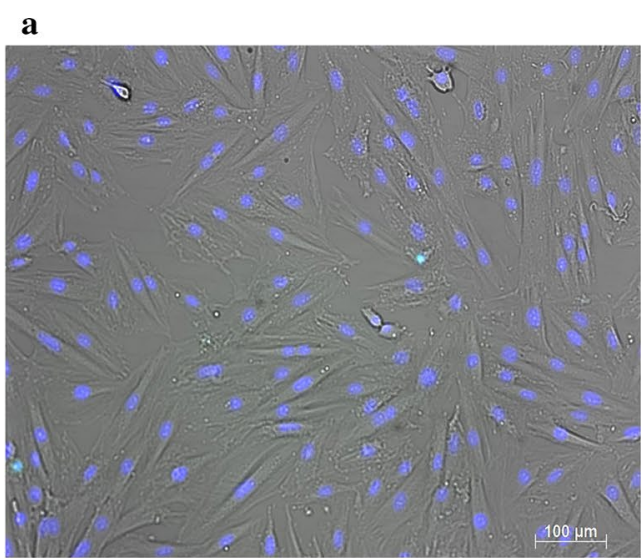

Control

b

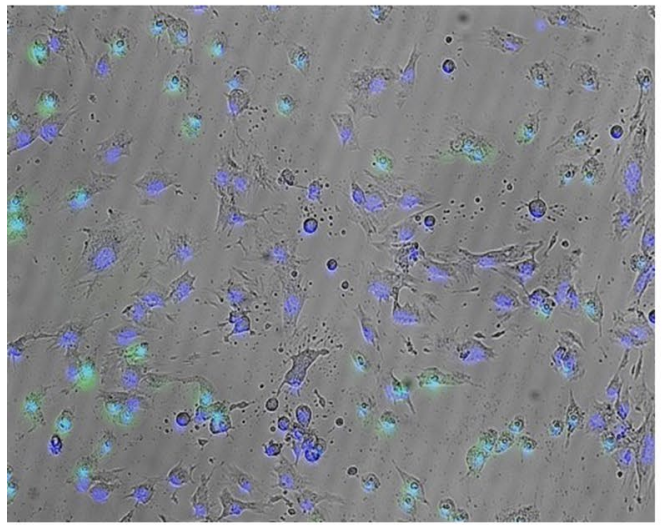

HCY 30

c

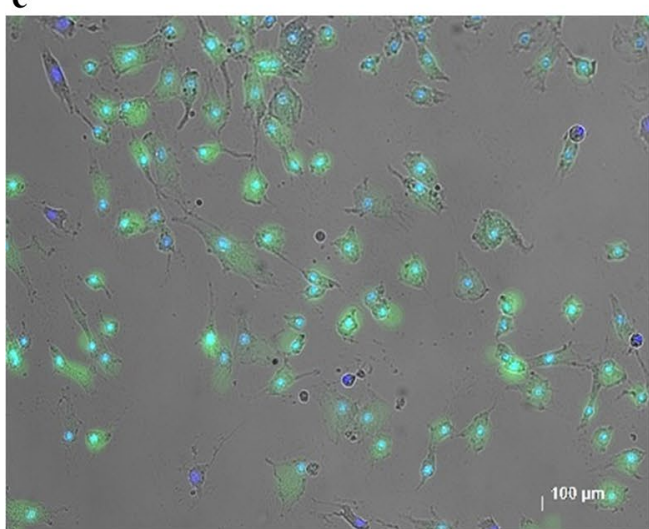

Acr 100 d

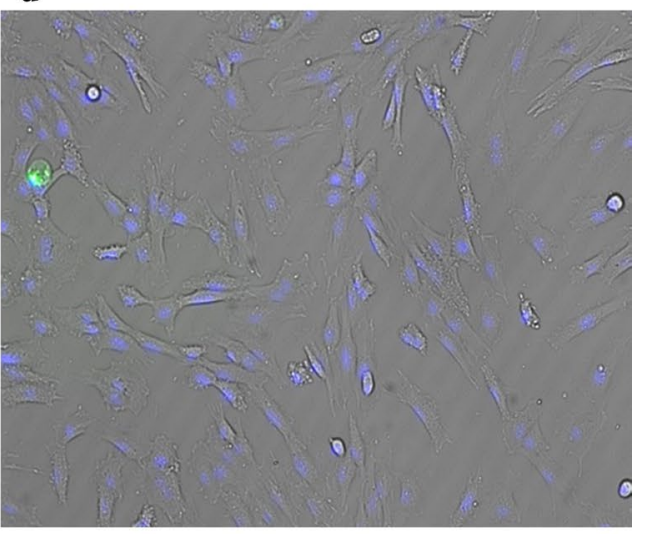

HCY $30+\mathrm{NAC}$

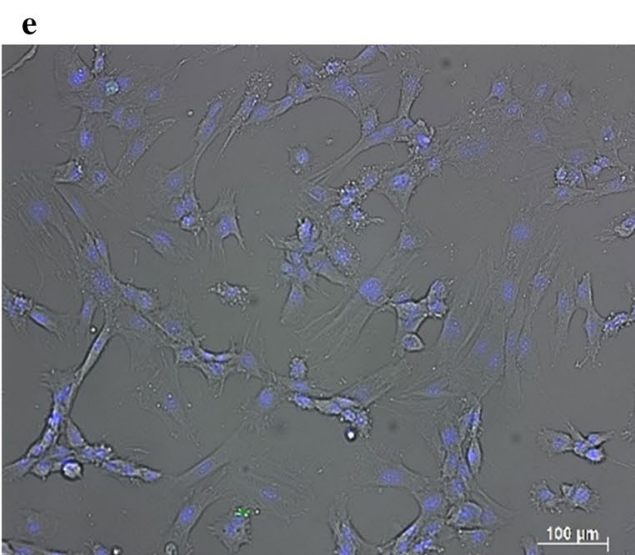

Acr $100+$ NAC

Fig. 4 Optical and fluorescence images of $\mathrm{H} 9 \mathrm{c} 2$ cells exposed, in presence or absence of NAC, to CY metabolites. a-e Optical images of samples after $24 \mathrm{~h}$ exposure: living cell nuclei stained by Hoechst 33342 are blue. Induction of apoptosis in H9c2 cells by CY metabolites in presence or absence of NAC: living cell nuclei stained by Hoechst 33342 are blue; apoptotic cells stained by FITC-conjugated probes are green. a Control (unexposed H9c2 cells); b H9c2 cells exposed to $30 \mu \mathrm{M} \mathrm{HCY}$; c H9c2 cells exposed to $100 \mu \mathrm{M}$ acrolein. $\mathbf{d} \mathrm{H} 9 \mathrm{c} 2$ cells exposed to $30 \mu \mathrm{M} \mathrm{HCY}$ with NAC; e H9c2 cells exposed to $100 \mu$ M acrolein with NAC. Magnification, $\times 100 ;$ bar $200 \mu \mathrm{m}$ 

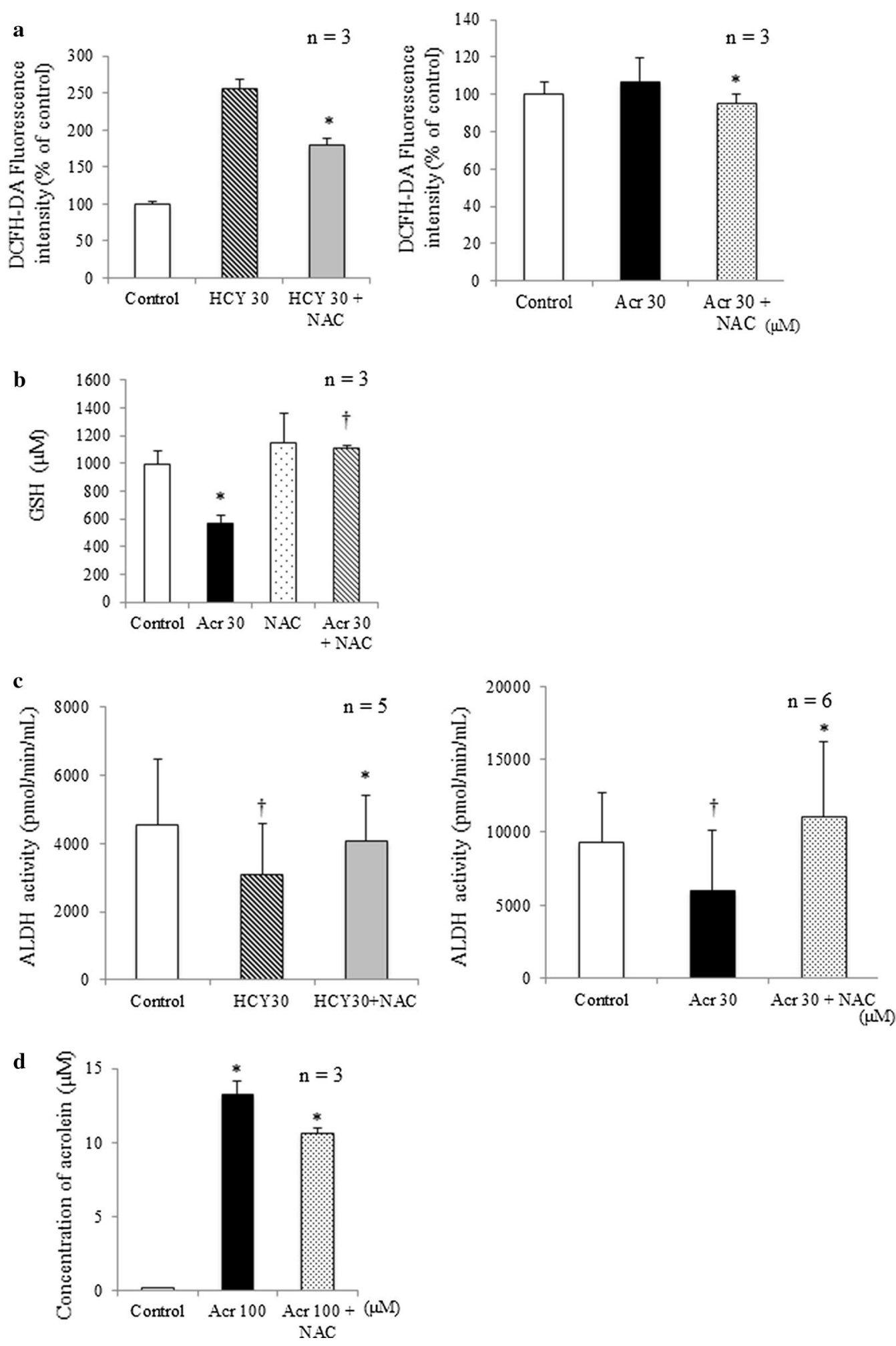
(See figure on previous page.)

Fig. 5 Various effects of NAC on H9C2 cells after exposure to CY metabolites. a ROS generation in H9c2 cells after exposure to HCY or acrolein in presence or absence of NAC. In H9c2 cell samples exposed to $30 \mu \mathrm{M} \mathrm{HCY}$ and $30 \mu \mathrm{M}$ acrolein for 15 min (mean + SD from three independent experiments), the presence of NAC prevented increased ROS generation. For control, unexposed H9c2 cells were used. ${ }^{*} p<0.05$ compared with samples without NAC. b Reduced glutathione levels in $\mathrm{H} 9 \mathrm{c} 2$ cells after exposure to acrolein in presence or absence of NAC. Effects of NAC on glutathione levels in $\mathrm{H} 9 \mathrm{c} 2$ cells exposed to acrolein for $2 \mathrm{~h}$ (mean $+\mathrm{SD}$ from three independent experiments). For control, unexposed H9c2 cells were used. ${ }^{*} p<0.05$ compared with control samples; ${ }^{\dagger} p<0.05$ compared with acrolein exposure. c ALDH activity in H9c2 cells after exposure to HCY or acrolein with and without NAC. Effects of NAC on ALDH activity in H9c2 cells exposed to $30 \mu \mathrm{M} \mathrm{HCY}$ and $30 \mu \mathrm{M}$ acrolein for $4 \mathrm{~h}$ (mean + SD from 5 to 6 independent experiments). For control, unexposed $\mathrm{H} 9 \mathrm{c} 2$ cells were used. Compared with control samples, ALDH activity decreased in $30 \mu \mathrm{M}$ $\mathrm{HCY}$ and $30 \mu \mathrm{M}$ acrolein. Presence of NAC prevented decrease in ALDH activity. ${ }^{\dagger} p<0.05$ compared with control group; ${ }^{*} p<0.05$ compared with samples without NAC. (D) Acrolein concentration in H9c2 cells after exposure to $100 \mu \mathrm{M}$ acrolein in presence or absence of NAC. H9c2 cells were exposed for $4 \mathrm{~h}$ to acrolein (mean + SD from three independent experiments). The changes of acrolein in culture media was measured using HPLC. The concentration of acrolein was decreased in the presence of NAC. ${ }^{*} p<0.05$ compared with $100 \mu \mathrm{M}$ acrolein without NAC

induced apoptosis [19-21]. GSH is a potent intracellular anti-oxidant and it has been reported that intracellular depletion of GSH enhances cytotoxicity and apoptosis [22]. In line with our previous findings [11], results in Fig. 5b indicate that while acrolein statistically significantly decreased intracellular GSH from the level in control samples, the presence of NAC was associated with increased intracellular GSH. This NAC-increased GSH level may play an important role in the mechanism protecting $\mathrm{H} 9 \mathrm{c} 2$ cells from the effects of CY metabolites.

In the $\mathrm{CY}$ metabolic pathway, AldoCY is metabolized to CEPM in the presence of ALDH [4]; if ALDH activity decreases, metabolism to CEPM is inhibited, and the level of acrolein increases. We previously found, compared with control samples, that pre-treatment with NAC statistically significantly increases CEPM concentration and decreases acrolein concentration, and concluded that NAC inhibits CYS9-induced cardiotoxicity [11]. Ren et al. have also reported that acrolein inhibits ALDH1 activity [23]. Here, we further found (Fig. 5c) statistically significantly less ALDH activity after exposure to HCY or acrolein, but that this decrease was counteracted by NAC. For H9c2 cells, this NAC-increased ALDH activity may also play an important role in the protective mechanisms.

Yoshida et al. have reported that NAC is a powerful scavenger of acrolein [12]. Indeed, we found that pre-treatment with NAC statistically significantly decreased acrolein concentration compared to control samples (Fig. 5d). In cell samples challenged by $\mathrm{CY}$ metabolites, directly scavenging acrolein, NAC promisingly maintained the level of ALDH activity. Cardiac myocytes may defend themselves against the cytotoxicity of high-dose $\mathrm{CY}$ by expressing ALDH, which plays a similar defensive role in cancer stem cells [24] and in hematopoietic stem cells [25].

\section{Conclusions}

Cardiotoxicity induced by $\mathrm{CY}$ is dose-dependently related to the presence of $\mathrm{HCY}$ and acrolein. Although high-dose $\mathrm{CY}$ therapy is an essential treatment for the eradication of tumor cells, some patients succumb to cardiotoxicity. Cardiotoxicity induced by high-dose $\mathrm{CY}$ is associated with ROS generation, GSH depletion, and lessened ALDH activity, and our findings suggest that NAC is likely to protect against CY-induced cardiotoxicity by counteracting these effects. NAC is widely used as a mucolytic agent [26] and as an antidote for hepatotoxicity cause by acetaminophen overdoses $[27,28]$. Furthermore, since for preventing oral mucositis in HSCT settings, NAC is already being used from day one in high-dose chemotherapy that may involve the use of CY, effective clinical application of NAC to prevent high-dose CY cardiotoxicity is feasible [29]. In clinical practice, by measuring acrolein in blood plasma and treating accordingly with $\mathrm{NAC}, \mathrm{CY}$-induced cardiotoxicity may be prevented.

\section{Abbreviations \\ ALDH: aldehyde dehydrogenase; CEPM: carboxyethylphosphoramide mustard; CY: cyclophosphamide; DCFH-DA: dichlorofluorescin diacetate; FITC: fluorescein isothiocyanate; GSH: glutathione; H9c2: rat cardiac myocardial cell line; HCY: 4-hydroxy-cyclophosphamide; HPLC: high performance liquid chro- matography; MTT: 3-(4,5-dimethyl-2-thiazolyl)-2,5-diphenyl-2H-tetrazolium bromide; NAC: $\mathrm{N}$-acetylcysteine; PBS: phosphate-buffered saline; ROS: reactive oxygen species.}

\section{Authors' contributions}

Conceived and designed the experiments: TN YK. Performed the experiments: KK EM. Analyzed the data: KKTN EM YO. Contributed reagents/materials/analysis tools: YO YK. Wrote the paper: KKTN EM. All authors read and approved the final manuscript.

\section{Acknowledgements \\ Not applicable.}

\section{Competing interests}

The authors declare that they have no competing interests.

\section{Availability of data and materials}

Data are available upon request from the corresponding author.

\section{Consent for publication}

Not applicable.

Ethics approval and consent to participate Not applicable. 


\section{Funding}

T. Nishikawa received a Grant from Scientific Research (C) from the Ministry of Education, Culture, Sports, Science and Technology of Japan (Web: https://kaken.nii.ac.jp/ja/grant/KAKENHI-PROJECT-16K10034/, Grant Number \#16K10034) The funders had no role in the study design, data collection and analysis, decision to publish, or preparation of the manuscript.

\section{Publisher's Note}

Springer Nature remains neutral with regard to jurisdictional claims in published maps and institutional affiliations.

Received: 27 September 2016 Accepted: 6 August 2017

Published online: 14 August 2017

\section{References}

1. Santos GW, Sensenbrenner LL, Burke PJ, Mullins GM, Blas WB, Tutschka PJ, et al. The use of cyclophosphamide for clinical marrow transplantation. Transplant Proc. 1972;4:559-64.

2. Eto M, Mayumi H, Tomita Y, Yoshikai Y, Nishimura Y, Maeda T, et al. Specific destruction of host-reactive mature T cells of donor origin prevents graft-versus-host disease in cyclophosphamide-induced tolerant mice. J Immunol. 1991;146:1402-9.

3. O'Donnell PV, Luznik L, Jones RJ, Vogelsang GB, Leffell MS, Phelps M, et al. Nonmyeloablative bone marrow transplantation from partially HLA-mismatched related donors using posttransplantation cyclophosphamide. Biol Blood Marrow Transplant. 2002;8:377-86.

4. Emadi A, Jones RJ, Brodsky RA. Cyclophosphamide and cancer: golden anniversary. Nat Rev Clin Oncol. 2009;6:638-47.

5. McDonald GB, Slattery JT, Bouvier ME, Ren S, Batchelder AL, Kalhorn TF, et al. Cyclophosphamide metabolism, liver toxicity, and mortality following hematopoietic stem cell transplantation. Blood. 2003;101:2043-8.

6. Atalay F, Gulmez O, Ugurlu AO. Cardiotoxicity following cyclophosphamide therapy: a case report. J Med Case Rep. 2014;8:252.

7. Dhesi S, Chu MP, Blevins G, Paterson I, Larratt L, Oudit GY, et al. Cyclophosphamide-induced cardiomyopathy: a case report, review, and recommendations for management. J Investig Med High Impact Case Rep. 2013;1:1-7.

8. Gottdiener JS, Appelbaum FR, Ferrans VJ, Deisseroth A, Ziegler J. Cardiotoxicity associated with high-dose cyclophosphamide therapy. Arch Intern Med. 1981;141:758-63.

9. Mills BA, Roberts RW. Cyclophosphamide-induced cardiomyopathy: a report of two cases and review of the English literature. Cancer. 1979;43:2223-6

10. Cazin B, Gorin NC, Laporte JP, Gallet B, Douay L, Lopez M, et al. Cardiac complications after marrow transplantation. A report on a series of 63 consecutive transplantation. Cancer. 1986:57:2061.

11. Nishikawa T, Miyahara E, Kurauchi K, Watanabe E, Ikawa K, Tanabe T, et al. Mechanism of fatal cardiotoxicity following high-dose cyclophosphamide therapy and a method for its prevention. PLOS ONE. 2015;10:e0131394.

12. Yoshida M, Tomitori H, Machi Y, Hagihara M, Higashi K, Goda H, et al. Acrolein toxicity: comparison with reactive oxygen species. Biochem Biophys Res Commun. 2009:378:313-8.

13. Alarcon RA. Fluorometric determination of acrolein and related compounds with m-aminophenol. Anal Chem. 1968:40:1704-8.

14. Bohnenstengel F, Eichelbaum M, Golbs E, Kroemer HK. High-performance liquid chromatographic determination of acrolein as a marker for cyclophosphamide bioactivation in human liver microsomes. J Chromatogr B Biomed Sci Appl. 1997;25(692):163-8.
15. DeJarnett N, Conklin DJ, Riggs DW, Myers JA, O'Toole TE, Hamzeh I, et al. Acrolein exposure is associated with increased cardiovascular disease risk. J Am Heart Assoc. 2014;3:e000934.

16. Luo C, Li Y, Yang L, Wang X, Long J, Liu J. Superparamagnetic iron oxide nanoparticles exacerbate the risks of reactive oxygen species-mediated external stresses. Arch Toxicol. 2015;89:357-69.

17. Cox PJ. Cyclophosphamide cystitis-identification of acrolein as the causative agent. Biochem Pharmacol. 1979;28:2045-9.

18. DeLeve LD. Cellular target of cyclophosphamide toxicity in the murine liver: role of glutathione and site of metabolic activation. Hepatology. 1996;24:830-7.

19. Asiri YA. Probucol attenuates cyclophosphamide-induced oxidative apoptosis, p53 and Bax signal expression in rat cardiac tissues. Oxid Med Cell Longev. 2010;3:308-16.

20. Sekeroğlu V, Aydin B, Sekeroğlu ZA. Viscum album L. extract and quercetin reduce cyclophosphamide-induced cardiotoxicity, urotoxicity and genotoxicity in mice. Asian Pac J Cancer Prev. 2011;12:2925-31.

21. Mansour HH, El Kiki SM, Hasan HF. Protective effect of $N$-acetylcysteine on cyclophosphamide-induced cardiotoxicity in rats. Environ Toxicol Pharmacol. 2015:40:417-22.

22. Jiang N, Dreher KL, Dye JA, Li Y, Richards JH, Martin LD, et al. Residual oil fly ash induces cytotoxicity and mucin secretion by guinea pig tracheal epithelial cells via an oxidant-mediated mechanism. Toxicol Appl Pharmacol. 2000;163:221-30

23. Ren S, Kalhorn TF, Slattery JT. Inhibition of human aldehyde dehydrogenase 1 by the 4-hydroxycyclophosphamide degradation product acrolein. Drug Metab Dispos. 1999;27:133-7.

24. Ginestier C, Hur MH, Charafe-Jauffret E, Monville F, Dutcher J, Brown M, et al. ALDH1 is a marker of normal and malignant human mammary stem cells and a predictor of poor clinical outcome. Cell Stem Cell. 2007;1:555.

25. Jones RJ, Barber JP, Vala MS, Collector MI, Kaufmann SH, Ludeman SM et al. Assessment of aldehyde dehydrogenase in viable cells. Blood. 1995;85:2742-6.

26. Rogers DF. Mucoactive agents for airway mucus hypersecretory diseases. Respir Care. 2007:52:1176-93.

27. Khayyat A, Tobwala S, Hart M, Ercal N. N-acetylcysteine amide, a promising antidote for acetaminophen toxicity. Toxicol Lett. 2016;241:133-42.

28. Smilkstein MJ, Knapp GL, Kulig KW, Rumack BH. Efficacy of oral $\mathrm{N}$-acetylcysteine in the treatment of acetaminophen overdose. Analysis of the national multicenter study (1976 to 1985). N Engl J Med. 1988;319:1557-62.

29. Moslehi A, Taghizadeh-Ghehi M, Gholami K, Hadjibabaie M, JahangardRafsanjani Z, Sarayani A, et al. N-acetyl cysteine for prevention of oral mucositis in hematopoietic SCT: a double-blind, randomized, placebocontrolled trial. Bone Marrow Transplant. 2014;49:818-23.

\section{Submit your next manuscript to BioMed Central and we will help you at every step:}

- We accept pre-submission inquiries

- Our selector tool helps you to find the most relevant journal

- We provide round the clock customer support

- Convenient online submission

- Thorough peer review

- Inclusion in PubMed and all major indexing services

- Maximum visibility for your research

Submit your manuscript at www.biomedcentral com/submit 